\title{
Dez anos dos Núcleos de Apoio à Saúde da Família (Nasf): problematizando alguns desafios
}

\author{
Ten years of Family Health Support Teams (Nasf): problematizing \\ some challenges
}

Eduardo Alves Melo', Lílian Mirandaㄹ, Atila Mendes da Silva ${ }^{\mathbf{3}}$, Rosana Mira Nunes Limeira4

DOI: $10.1590 / 0103-110420185122$

1 Fundação Oswaldo Cruz (Fiocruz), Escola Nacional de Saúde Pública Sergio Arouca (Ensp) - Rio de Janeiro (RJ), Brasil. Orcid: https://orcid org/0000-0001-58814849

eduardo.melo@ensp. fiocruz.br

2 Fundação Oswaldo Cruz (Fiocruz), Escola Nacional de Saúde Pública Sergio Arouca (Ensp) - Rio de Janeiro (RJ), Brasil. Orcid: https://orcid. org/0000-0002-82388111

lilian.miranda@ensp.

fiocruz.br

${ }^{3}$ Fundação Oswaldo Cruz (Fiocruz), Escola Nacional de Saúde Pública Sergio Arouca (Ensp) - Rio de Janeiro (RJ), Brasil. Orcid: https://orcid. org/0000-0001-6745$868 \mathrm{X}$

atilams1@yahoo.com.br

4 Universidade Federal Fluminense (UFF), Programa de Pósgraduação em Psicologia (PPGP) - Niterói (RJ), Brasil.

Orcid: https://orcid. org/0000-0002-48890757

rosanamnlimeira@gmail. com

\section{Introdução}

A Atenção Básica (AB) ganhou destaque na década de 90 do século passado, em um processo que passou pela criação do Programa de Agentes Comunitários de Saúde (Pacs), em 1991, pelo Programa de Saúde da Família (PSF), em 1994, reordenados com a Estratégia Saúde da Família (ESF), em 1996. Considerada não apenas um novo modo de organização da AB, mas também um mecanismo de reorientação do modelo assistencial', a ESF se expandiu no País ao longo das últimas décadas, materializando-se por meio das Equipes de Saúde da Família (EqSF), compostas por médicos, enfermeiros, técnicos de enfermagem e agentes comunitários de saúde (com agregações e ajustes nessa composição ao longo do tempo, como as equipes de saúde bucal).

A ESF passou a ser a principal modalidade de AB induzida (inclusive financeiramente) no Sistema Único de Saúde (SUS) a partir de recursos federais, agregando novas lógicas e mecanismos de funcionamento, a exemplo do Piso de Atenção Básica (PAB) Fixo (per capita) e do PAB Variável (por adesão a estratégias), operados por meio de transferências diretas do Fundo Nacional de Saúde para os Fundos Municipais de Saúde. A sua implantação se deu de maneira progressiva, com destaque inicial para os municípios menores, mais pobres e da região Nordeste, depois expandindo-se também nas grandes cidades ${ }^{2}$ e constituindo-se em uma das principais evidências do grau de descentralização que o SUS assumiu ${ }^{3}$. Esse processo, em que pese o êxito da ampliação de cobertura da ESF e seus efeitos no acesso e em indicadores de saúde da população ${ }^{4}$, também foi alvo de críticas, em função de questões como, por exemplo, o caráter seletivo e simplificado de uma atenção primária focalizada (sobretudo nos anos 1990), a não integração a uma rede de serviços, a não valorização do tema dos cuidados clínicos e individuais, a alta normatividade, bem como as próprias condições materiais de implantação das EqSF5 5 .

Em 2008, 14 anos após a criação da ESF e intenso processo de discussões e negociações no âmbito federal, foram criados os Núcleos de Apoio à Saúde da Família (Nasf), sob influência de algumas experiências municipais, de formulações no campo da saúde coletiva e de 
reivindicações corporativas. A normativa oficial que instituiu o Nasf o define como equipe de apoio às EqSF, não o constituindo como porta de entrada, e indicando como seu objetivo a ampliação do escopo de ações e da resolutividade da AB. Para tanto, supõe que opere em lógica diferente daquela presente nas noções de encaminhamento, referência e contrarreferência ${ }^{6}$. Nessa normativa, também se destacaram a previsão de dois tipos de Nasf, a presença da saúde mental na composição das equipes, bem como a prerrogativa da gestão municipal de definir a composição de categorias profissionais do Nasf no âmbito local, observando as regras gerais.

Nos anos seguintes, iniciou-se a implantação dos Nasf em diversos municípios brasileiros, chegando, segundo dados do Ministério da Saúde (MS), a 1.317 no ano de 20107. Esse processo foi acompanhado, por um lado, de certo otimismo gerado pela perspectiva de fortalecimento da $\mathrm{AB}$ e incorporação de novas práticas e, de outro, pela dificuldade de traduzir a sua lógica de trabalho, centralmente calcada na noção de Apoio Matricial (AM) ${ }^{\mathbf{8}}$. Um dos problemas evidenciados nesse processo foi o alto número de EqSF por Nasf, dificultando, ou mesmo impedindo, na prática, a sua efetivação.

A esse respeito, é oportuno também indicar que o Nasf fora implementado em contexto dos mesmos problemas enfrentados pela ESF, com os quais passou a conviver, tais como precariedade da infraestrutura logística e física das Unidades Básicas de Saúde (UBS), alta rotatividade de profissionais (especialmente médicos), dificuldades na organização dos processos de trabalho e baixa integração com demais serviços das redes locorregionais 9 ,10.

A partir de 2011, houve importante inflexão na Política Nacional de Atenção Básica (PNAB), que passou a ocupar centralidade na agenda federal e tripartite. Nesse processo, destacaram-se algumas medidas: incorporação de modalidades de equipes (as equipes ribeirinhas e fluviais, bem como os
Consultórios na Rua), criação do Programa de Requalificação de UBS (com reformas, ampliações, construções, informatização e Telessaúde), do Programa de Melhoria do Acesso e da Qualidade (PMAQ) e, em 2013, do Programa Mais Médicos (PMM) para o Brasil. Especificamente para o Nasf, ocorrera significativa revisão normativa em 2012, quando passou-se a prever: criação de mais de um tipo de equipe, contemplando municípios de pequeno porte; incorporação de novos profissionais e ocupações; e diminuição substancial do número de EqSF a serem cobertas $^{11}$. A isso, somou-se, nos anos seguintes, uma nova publicação nacional com orientações e recomendações ${ }^{\mathbf{1 2}}$; a inclusão dos Nasf no PMAQ, bem como a primeira oferta, em escala nacional, de um curso para seus profissionais, inspirado nos referenciais da Educação Permanente em Saúde (EPS) e nas noções de Apoio Institucional (AI) e Matricial ${ }^{13}$.

Em termos de presença dos Nasf no País, em 2013, havia 2.767 implantados, passando a 4.288 em 2015, 4.406 em 2016, a $4.886 \mathrm{em}$ 2017 e a 5.221 em março de 20187. Observase, nesse período, maior crescimento entre os Nasf existentes em pequenos municípios, e presença frequente de psicólogos, nutricionistas e fisioterapeutas.

Recentemente, em 2017, foi publicada uma nova edição da PNAB, diante de muitos protestos e questionamentos de atores e segmentos do SUS e da saúde coletiva, em uma conjuntura de ataques a todas as políticas sociais. Ainda que nessa PNAB não tenha havido mudanças estruturais importantes no Nasf, chama a atenção o fato de que ela amplia sua responsabilidade para as chamadas equipes de $\mathrm{AB}$ tradicionais, retira $\mathrm{o}$ termo apoio da sua nomenclatura, gerando dúvidas sobre o lugar que o matriciamento passa a ter aos gestores responsáveis pela implementação das mudanças, além de colocar em risco a própria ESF.

As formulações e decisões sobre o Nasf, traduzidas em portarias nacionais, tiveram influência sobre sua implantação. No 
entanto, sua trajetória normativa não se reflete automaticamente nas realidades locais e cotidianas, especialmente em um país diverso e desigual como o Brasil. Além disso, o tempo apenas uma década - e a complexidade da sua implementação impõem importantes especificidades entre os modos de operação pelo País.

Nessa conjuntura, o objetivo deste artigo, portanto, escrito sob a forma de artigo de opinião, é problematizar alguns desafios colocados aos Nasf, considerando os 10 anos de sua presença na PNAB. Abordaremos, centralmente, questões relacionadas com conceitos e propostas que o envolvem, bem como com o modelo e estratégias de gestão e organização do trabalho em saúde que devem subsidiá-lo.

\section{Refletindo sobre a formulação teórico- conceitual e metodológica do Nasf}

As especificidades no modo de implantação e operação do Nasf pelo País têm gerado polêmicas e dicotomias relacionadas, principalmente, com a sua atuação em atividades individuais (consultas) e ações coletivas (grupais, educativas) ou, ainda, entre a assistência que os matriciadores oferecem diretamente à população e aquela que o fazem em colaboração com a EqSF de referência dos usuários. Trata-se de questões que possivelmente decorrem da dificuldade de tradução da noção de AM no contexto da ESF, do receio de que profissionais do Nasf operem como um ambulatório de especialidades tradicional, bem como da suposição, a nosso ver equivocada, de certa homogeneidade entre as ações das diferentes categorias (como se o tipo e o tempo das atividades do psicólogo precisassem coincidir com aquelas próprias aos fisioterapeutas e nutricionistas, por exemplo) ${ }^{14-16}$. Acresce-se a isso o entendimento, até pouco tempo muito forte, de que na ESF se faz prioritariamente (ou quase que exclusivamente) promoção e prevençãa ${ }^{17,18}$, ainda que as normativas oficiais suponham, desde 2006, maior abrangência de ações assistenciais ${ }^{19}$.

A compreensão dos possíveis elementos geradores das dicotomias que envolvem o Nasf não nos exime de enfatizar que estas devem ser superadas, na medida em que cabe aos seus profissionais justamente a integração entre ações de caráter pedagógico com aquelas que, embora consideradas assistenciais, sempre são feitas com algum grau de participação da equipe mínima. Fundamentadas na noção de 'apoio matricial'8, as diretrizes oficiais de funcionamento do Nasf indicam uma organização do cuidado baseada na colaboração entre equipes responsáveis por um determinado território e no compartilhamento de saberes e práticas entre apoiadores matriciais e EqSF. Supõem não apenas a presença de um profissional com o mandato de apoiador e qualificação de especialista, mas a realização de encontros deste com a equipe e os usuários. Para tanto, preconizam ações, como discussões de caso, atendimentos compartilhados entre Nasf e EqSF (ou protagonizados pelos primeiros, mas precedidos/sucedidas por discussão com as equipes), construção conjunta de projetos terapêuticos, educação permanente, intervenções no território, ações intersetoriais, ações de prevenção e promoção, reflexões conjuntas sobre o processo de trabalho, entre outras ${ }^{20}$.

Cabe aqui distinguir o AM do AI, embora partam de uma raiz comum. No AI, a principal tarefa é ofertar suporte para as transformações institucionais, fortalecendo os sujeitos e as instituições para a construção de modos gestão mais democráticos, tendo como objeto principal o próprio processo de trabalho ${ }^{21}$. Tarefa também presente no $\mathrm{AM}$, que mantem alguns princípios do AI, ao passo que traz novas proposições: atuação a partir de um núcleo de saber e relação mais próxima aos usuários, por exemplo. O AI é mais direcionado à gestão do processo de 
trabalho; e o AM, à gestão e produção do cuidado em si, embora tais dimensões sejam de difícil separação na prática.

O apoiador, ainda que de modos próprios (matricial e/ou institucional), habita a fronteira entre a clínica e a política, entre a gestão e o cuidado, trabalhando no sentido transversal, articulando saberes e práticas das organizações apoiadas, em prol da produção de saúde ${ }^{21}$. A função apoio comparece, assim, como diretriz e dispositivo que a visa ampliar a capacidade de análise e intervenção dos coletivos (das EqSF, neste caso).

O AM, em sua formulação, coloca-se a serviço da compreensão e manejo de problemas de saúde e histórias de adoecimento e sofrimento, compartilhando saberes com generalistas ou responsáveis mais diretos pelos casos, realizando práticas conjuntas por meio de interações pedagógicas próximas do cenário concreto dos profissionais e usuários, tendo potencial de reordenar o lugar e as práticas dos especialistas ${ }^{8}$. Essas práticas requerem capacidades que se inserem em um terreno ao mesmo tempo técnico, micropolítico e relacional, razão pela qual, com outros autores $^{22}$, consideramos que a prática do AM pode requerer elementos de AI, exercidas diretamente pelo matriciador e/ou com o suporte de pessoas que operem na lógica do AI.

O Nasf ou o AM não correspondem exatamente a nenhuma experiência no contexto internacional, mas podem ser aproximados de diferentes arranjos que propõem trabalho conjunto, tais como Consultation-liaison e Colaborative care ${ }^{23-25}$. Originadas em contexto anglo-saxão ou norte-americano, a maior parte das experiências internacionais de trabalho colaborativo não contempla, ou não enfatiza, questões relacionadas com a gestão do processo de trabalho (democratização das relações de poder entre categorias profissionais, por exemplo). De modo geral, pressupõem a presença de um gestor de caso, responsável por ações diretas com usuários, interconsultas e viabilização da ligação entre atenção primária e especializada, indicando a função de coordenação de caso, que se aproxima de um dos papeis do apoiador matricial (nos momentos em que os usuários se encontram em situações mais críticas, por exemplo). Contudo, trata-se de um trabalho bastante prescritivo, com priorização de indicações claras e pragmáticas sobre o modo como o trabalho de colaboração deve funcionar, as especificidades dos papéis de cada ator, bem como os resultados esperados 23-25.

Com ações e resultados que, em geral, não se baseiam em protocolos ou metas preestabelecidas, a amplitude de possibilidades de ação do Nasf não é sentida por grande parte dos profissionais como propiciadora, predominantemente, de criatividade e autonomia no trabalho. Muitos avaliam que sua proposta é ambígua, pois aponta algumas funções sem definir atividades que obrigatoriamente devam ser realizadas, o que produziria certo descontrole dos resultados do trabalho ${ }^{26}$. Nesse sentido, estudos mostram profissionais de Nasf que priorizam discussão de caso e atenção compartilhada com a equipe, oferecem apoio para as relações interprofissionais (exercendo, em algumas situações, a função de AI), ao mesmo tempo que existem aqueles que atuam como supervisores e consultores ou, por outro lado, exercem práticas clínicas de modo isolado, sem compartilhamento com a equipe ${ }^{9,14-16,27}$.

Pesquisas indicam, ainda, que os profissionais do Nasf se queixam de má formação para o exercício do AM e de dificuldade para legitimar práticas interdisciplinares nas EqSF. Ante essas questões, solicitam reformulações das normativas, de modo que estas evidenciem quais as funções de cada profissão 14-17,26. Para Correia, Goulart e Furtado ${ }^{\mathbf{2 6}}$, encontramo-nos diante de um paradoxo, na medida em que se busca nos núcleos de saber respostas para dificuldades que se encontram justamente em um campo não só de interpenetração destes, mas também de extrapolação deles (o campo da construção conjunta dos projetos terapêuticos, ou da análise de processos de trabalho, por exemplo).

Em uma perspectiva diferente, lembrando 
que a proposta de AM envolve a função de suporte técnico-pedagógico, bem como de prestação de cuidado especializado, Tesser ${ }^{17}$ defende que, equivocadamente, tem-se dado ênfase à primeira. Embora pondere que ambas as funções só se efetuam se desempenhadas de modo sinérgico, observa que os textos oficiais supervalorizam ações interdisciplinares a ocorrerem com a presença física dos diferentes profissionais, com objetivos, principalmente, de promoção e prevenção de saúde, planejamento e atuação no território. Para o autor, há um exagero na indução de compartilhamento constante das práticas, pois o cuidado especializado pode ter um componente interdisciplinar, mesmo que exercido apenas pelo especialista.

Na avaliação de Tesser ${ }^{17}$, as ações 'eminentemente interdisciplinares' colocariam os 'nasfianos' em uma posição de 'generalista' para a qual não foram formados, esvaziando ou enfraquecendo a função de especialista e induzindo a desvalorização simbólica e ideológica do cuidado especializado no SUS. Trata-se de um problema que se acentua porque, concomitantemente, desvaloriza-se também a competência específica dos generalistas (já que se supõe que os 'nasfianos' também podem realizá-la). Nesse processo, ao sobrecarregarem-se com atividades generalistas, os apoiadores deixam de compartilhar a pressão assistencial com as EqSF, afastando-se delas.

A nosso ver, essas questões devem ser enfrentadas cuidadosamente. Porém, não consideramos que devam ser minimizadas por meio de mudanças nas normativas do Nasf, de modo a induzir um aumento do cuidado especializado a ser exercido pelos apoiadores matriciais. Consideramos, pelo contrário, que a priorização de um tipo ou outro de prática deve ser dada pelos contextos locais, a depender de suas necessidades proeminentes. Ademais, avistamos que analisar o AM a partir de dicotomias (especialismo/generalismo; apoio pedagógico/atendimento ambulatorial) pode incorrer em riscos ainda maiores, pois denega seu lugar intersticial: entre a equipe e a gestão, entre a gestão da área programática/distrito de saúde e a gestão da unidade básica, entre a equipe e o território, entre a equipe e o usuário.

Por posicionar-se nesse lugar intermediário, o Nasf nos coloca a necessidade de um questionamento acerca de questões referentes à colaboração interprofissional na relação entre equipes de natureza matriciais e de referência. Como sabemos, embora constituído como equipe distinta das EqSF, de acordo com o MS, o Nasf deve se manter integrado a estas, além de apoiá-las na articulação com outros pontos da rede de saúde e intersetorial12. Assim, a compreensão dos processos de colaboração pode ser útil para explorar a transição para formas mais integradas de organização ${ }^{\mathbf{2 8}}$, na medida em que o trabalho colaborativo busca responder à necessidade de reagrupamento de conhecimentos fragmentados, como forma de diminuir a alienação do trabalhador e evitar a duplicidade de cuidados ${ }^{29}$.

A colaboração é um processo complexo e dinâmico, que compreende, simultaneamente, a construção de uma ação coletiva, voltada para a complexidade das necessidades do usuário, e de uma vida em equipe, além de integrar as perspectivas de cada profissional, lidando com suas contradições e confli$\operatorname{tos}^{29}$. A integração da equipe requer tempo e investimento, pois se refere ao campo dos valores, do diálogo entre as competências, do exercício da autonomia, entendida como relação entre os saberes profissionais, mas também dos limites destes diante das necessidades de saúde dos usuários ${ }^{30}$. Nesse caminho, podemos compreender que parece ingênuo pensar que simplesmente colocar os profissionais juntos produzirá a colaboração. Consequentemente, no que se refere ao Nasf, é importante refletir que as relações matriciais também são complexas e implicam lidar ainda com os limites e possibilidades impostas pela posição de 'intermediário’.

A posição de intermediário ocupada pelo 
Nasf, tal como apontamos acima, implica que a realização de seu trabalho está em um constante trânsito entre a identificação com as EqSF (algo que pode favorecer a construção de vínculos, por meio de um envolvimento com os problemas enfrentados no cotidiano profissional da $\mathrm{AB}$ ) e a diferenciação (um distanciamento necessário para manter o estranhamento e contribuir com a transformação de crenças, posturas e práticas instituídas). Deter-se a um desses polos (identificação/diferenciação) impossibilitaria a realização de um apoio efetivo.

Assim, o exercício do AM exige, por definição, a sustentação de um paradoxo, na medida em que, caracterizado como retaguarda especializada, ele tem o objetivo de romper com a lógica especializada habitual. Inserido na APS, ele compartilha o trabalho com as EqSF, mas não faz parte delas: para compartilhar, precisa inserir-se nelas. Contudo, a fim de fazê-lo sob a forma de apoio, deve guardar a externalidade necessária para questionar os movimentos instituídos e colocá-los em análise.

Lidar com as contradições inerentes ao AM pode ser extremamente difícil, sobretudo na realidade da maior parte das unidades de saúde do País, submetidas à pressão da demanda oriunda de territórios marcados pela precariedade socioeconômica, por diferentes formas de violência e por limites na oferta e organização dos serviços especializados. Assim, 10 anos após a criação do Nasf, identificamos que um dos principais desafios é a elaboração de reflexões e estratégias de apoio aos seus profissionais. Estratégias que indiquem direcionamentos mais claros para suas ações, mas que não desconsiderem a complexidade inerente à função do AM. Se não o fizermos, corremos o risco de esvaziar seu sentido, tal como é possível antever nas propostas da nova PNAB ${ }^{31}$. Portanto, ao contrário de propor mudanças normativas que especifiquem ou objetivem as funções do Nasf, apostamos na criação de modos de lidar com os efeitos da diversidade identificada nos documentos oficiais já existentes.

Entre os aspectos a serem considerados nessa reflexão acerca do apoio a ser oferecido ao Nasf, estão questões estruturais (como recursos financeiros, materiais/meios de trabalho), de formação (inclusão de formação de AM nas residências de saúde, por exemplo), mas também de gestão e de rede, tal como discutiremos a seguir.

\section{O trabalho de apoio do Nasf na rede de atenção à saúde}

Compreende-se que a $\mathrm{AB}$ tem por função atuar como importante centro de comunicação entre os diversos serviços de saúde e, para isso, deve elaborar, acompanhar e gerir projetos terapêuticos singulares, bem como acompanhar e organizar o fluxo dos usuários entre os pontos das Redes de Atenção à Saúde (RAS) ${ }^{32,33}$. No entanto, apesar do desenvolvimento da $\mathrm{AB}$ no Brasil, alguns estudos têm apontado que esta ainda não reúne condições materiais e simbólicas para garantir o acesso e a articulação com os demais pontos de conexão do sistema, o que coloca a coordenação da atenção ainda como um desafio que depende, entre outros elementos, do desenvolvimento de arranjos de comunicação e da troca de informações entre os serviços ${ }^{34}$. Dessa forma, a descontinuidade e a fragmentação de projetos terapêuticos tornam-se mais acentuadas quando o cuidado iniciado na $\mathrm{AB}$ depende de outro serviço integrante do sistema de saúde ${ }^{8}$. Há, portanto, a necessidade de incremento da colaboração entre estes diferentes serviços para diminuir tal fragmentação e, com isso, obter melhoria do cuidado.

Nesse cenário, a atuação do Nasf é fundamental, pois, conforme apontamos anteriormente, este tem como função, além de apoiar a atuação das EqSF em seu processo de trabalho, auxiliá-las em sua articulação com os outros pontos da rede, bem como com os equipamentos sociais disponíveis nos 
territórios, ampliando, portanto, as possibilidades de coordenação do cuidado.

É possível analisar a colaboração entre profissionais de saúde tanto em equipes quanto entre organizações e em redes integradas de cuidados, considerando características que envolvem sua configuração organizacional e aspectos atrelados às relações entre os sujeitos ${ }^{28}$.

Quanto à configuração organizacional, estudos apontam a necessidade de formalização dos processos de colaboração em que se esclareçam as expectativas e responsabilidades dos atores, bem como uma governança que direcione e apoie as inovações relativas à colaboração interprofissionais e inter-organizacionais ${ }^{28}$. No caso dos Nasf, tem sido destacada a importância de algumas estratégias organizacionais, como: a discussão e pactuação de critérios de acionamento do AM; a elaboração, na rede de saúde, de protocolos de acesso/fluxo de encaminhamentos para outros pontos da rede; além da criação de espaços coletivos/cogestão e elaboração de processos de comunicação ágeis ${ }^{\mathbf{1 2}}$.

Já no que se refere aos aspectos relacionais envolvendo os trabalhadores das diferentes equipes e serviços implicados na realização de uma linha de cuidado, estudos ressaltam a necessidade de que haja compartilhamento de visão e objetivos, ao mesmo tempo que se reconheça a existência de motivações divergentes e múltiplas alianças entre os trabalhadores. Além disso, apontam como característica para a colaboração a consciência dos profissionais de sua interdependência e da importância de geri-la, o que se traduz em um sentimento de pertença e confiança mútua ${ }^{28}$.

Esses são alguns atributos importantes a se observar no trabalho de apoio dos Nasf e sua relação com a rede de saúde, porém trata-se de características sujeitas a influências externas e a fatores estruturais como recursos e políticas, que também são determinantes para a colaboração.

A dificuldade relativa à disponibilidade e modo de funcionamento da atenção especializada é apontada como um problema estrutural do SUS, que influencia a realização do trabalho do $\mathrm{Nasf}^{35}$. Em algumas experiências de implantação, devido à escassez de serviços especializados, ocorre uma utilização equivocada dos Nasf de maneira substitutiva a tais serviços. Assim, os Nasf são vistos como um modo de suprir uma falha da rede de saúde quanto à ausência de centros de serviços especializados, aproveitando um recurso disponível que não foi previsto para tal função ${ }^{36}$. Nesse sentido, é importante afirmar que o cuidado especializado é necessário para a efetividade do cuidado iniciado na $\mathrm{AB}$, de tal forma que sua disponibilidade no sistema é necessária para viabilizar a integralidade da atenção.

A rede de cuidados especializados é reconhecida como heterogênea e insuficiente, constituindo um gargalo para o sistema de saúde ${ }^{35,37,38}$. Há, em muitas regiões do País, insuficiência na oferta de serviços e carência de profissionais (em especial, médicos especialistas), bem como dificuldades na regionalização e dependência do setor privado que reforçam a fragmentação do sistema ${ }^{37}$. Além da carência de serviços referentes à atenção especializada, estudos apontam a necessidade de construção de diretrizes operacionais claras e de recursos para sua estruturação em um formato organizativo que possa ser induzido nacionalmente, como ocorreu com a ESF ${ }^{38}$. Tesser e Poli-Neto, por exemplo, defendem a necessidade de elaboração e indução de um formato organizacional para os serviços de cuidado especializados que tome por base a experiência dos Nasf ${ }^{38}$.

A metodologia do AM, que não se restringe à atuação do Nasf, quando utilizada por serviços especializados, pode ser uma forma de qualificar o cuidado, diminuindo o número de encaminhamentos desnecessários da $\mathrm{AB}$ e facilitando o compartilhamento do cuidado. Por exemplo, as reuniões para discussão de casos complexos e para pactuação dos fluxos assistenciais podem operacionalizar um uso mais eficiente dos serviços especializados e, com isso, possivelmente diminuir a medicalização e tornar o acesso mais equânime. Além disso, essa proposta poderia expandir 
a vivência de $\mathrm{AM}$ na realidade da produção do cuidado e da comunicação entre serviços, tornando-a uma metodologia mais usual nos processos de colaboração no cotidiano dos profissionais de saúde.

Ao mesmo tempo, o modo como o Nasf é estruturado e posto a operar também pode ser atravessado pelas características do território e da rede em que é implantado. Por exemplo, o lugar do Nasf na rede, bem como seu processo de trabalho na EqSF, em um município que possui grande disponibilidade de serviços ligados à reabilitação (centros de reabilitação, ambulatórios etc.), será, provavelmente, diferente do seu lugar em um município pequeno em que os únicos fisioterapeutas são seus integrantes. Nesse ponto, mostra-se profícuo entender a implantação-composição dos Nasf e o desenho da rede considerando a influência mútua entre eles na composição das linhas de cuidado.

É importante salientar que a integração entre os serviços é um processo, e não um evento, de modo que a própria implantação do Nasf pode ser um disparador de mudanças nos processos de trabalho e nos modos de produzir cuidado em rede. Nesse sentido, podemos compreender que o Nasf, ao se inserir no cotidiano da EqSF, tem potencial de gerar uma reestruturação produtiva ${ }^{39}$, a qual pode ser verificada quando a produção do cuidado se faz a partir das relações em rede entre os trabalhadores e nos modos de construir planos de cuidado na intercessão com os usuários.

De maneira semelhante, o Nasf talvez tenha o potencial de provocar uma reorientação da rede assistencial por meio do aumento do escopo de atuação da EqSF e da reorganização dos modos de produzir o cuidado na AB. Assim, pode ser revisto, por exemplo, em que medida alguns tipos de ofertas têm que se localizar na atenção especializada ou podem ser realizadas diretamente na $A B$ via Nasf.

Diante do que foi exposto, compreendemos que o Nasf, ao mesmo tempo que enfrenta o desafio de amplificar a colaboração com as EqSF e com outros pontos das redes de atenção, também pode ser visto como um dispositivo que, por meio de sua atuação, tem potencial de influenciar o modo como as equipes produzem cuidado e se relacionam com os outros serviços necessários para viabilizar atenção integral aos usuários.

As formas por meio das quais o Nasf pode atuar em favor da coordenação e integração do cuidado envolvem elementos normativos, metodológicos, relacionais e estruturais, como foi apontando, mas também exigem certas especificidades do campo da gestão, tal como passamos a discorrer.

\section{A gestão como um nó crítico para o Nasf}

Outro importante desafio para a operacionalização do Nasf diz respeito à sua relação com os processos de gestão, sejam os constitutivos da função apoio que possui uma dimensão de gestão implícita no seu trabalho, como, por exemplo, análise das relações de poder no processo de trabalho e planejamento das ações de cuidado; ou aqueles relacionados com a atuação dos gestores municipais e das unidades de saúde para que o trabalho desse núcleo aconteça.

Diferentemente das dimensões técnico-pedagógica e clínico-assistencial, as dimensões de gestão e de educação permanente se apresentam de forma transversal no trabalho do apoiador. Observa-se mais claramente a dimensão de gestão no trabalho do Nasf quando o apoiador é convidado a participar da discussão, organização e planejamento do processo de trabalho das equipes de referência, ou para apoiar a gestão dos serviços (coordenadores, diretores e/ou gerentes). Trata-se das situações em que o apoiador matricial exerce, em algum grau, a função de apoio institucional, tendo como foco o processo de trabalho das equipes de referência.

Essa dimensão também se refere à própria gestão da equipe Nasf, na medida em que é considerada, por exemplo, a necessidade de definir quando, onde e como os apoiadores se 
reúnem para organizar o seu trabalho. A complexidade do trabalho do Nasf - incluindo aqui a heterogeneidade na composição das equipes e a diversidade de atividades ofertadas - exige dos apoiadores um alto grau de organização das agendas de trabalho, uma vez que ações interdisciplinares requerem integração entre as atividades dos apoiadores e das EqSF. Vale ressaltar, ainda, a necessidade de graus de flexibilidade na construção da agenda, de forma a não produzir barreiras de acesso ao Nasf.

Essa dimensão de gestão do trabalho do apoio precisa ser considerada pelos gestores, equipes apoiadas e pelos próprios trabalhadores do Nasf. Ao problematizar o processo de trabalho das EqSF e ao transitar pela rede, por exemplo, o apoiador pode desvelar problemas relacionados com o modo de organização e gestão dos serviços, produzindo desconforto nos atores envolvidos. Por isso, aspectos como disponibilidade ao apoio e credibilidade acerca do seu trabalho intercessor - transitando entre os espaços e funções da rede - fazem-se imprescindíveis para o desenvolvimento da dimensão de gestão do apoio matricial.

Esse quadro indica que o trabalho do apoio pode ser potencializado a depender de algumas condições organizacionais ${ }^{21}$ disponibilizadas ou não pelos gestores locais; a começar pela abertura institucional para mudanças e pelo desejo de uma diretriz democratizante para o trabalho, compreendendo que o compartilhamento do cuidado, a troca de saberes, o trabalho em equipe são mais bem garantidos em ambientes organizacionais menos hierárquicos e mais participativos.

Outro aspecto condicionante para que o trabalho do Nasf se efetive diz respeito à forma como os gestores fazem a estruturação e a pactuação do trabalho do Nasf. São potencialmente influenciadores das práticas do AM alguns elementos básicos, como: o número de profissionais e as categorias que irão compô-lo; o número de EqSF a serem apoiadas; as características do território; além de garantias estruturais, como transporte, materiais, insumos, espaço físico para desenvolvimento das atividades ${ }^{\mathbf{1 2}}$.

Além disso, observa-se que a flexibilidade inerente ao trabalho do Nasf - por se tratar de um arranjo que permite uma grande diversidade de atividades, podendo ocorrer em diversos pontos da rede intra e intersetorial exige que os gestores ofertem condições para que os apoiadores construam uma agenda de trabalho que preveja esse trânsito entre os serviços e entre as equipes apoiadas. Isso demanda um grau importante de confiança dos gestores para com seus apoiadores matriciais e auxílio para abertura de canais institucionais, quando necessário.

Parece-nos fundamental, ainda que, a gestão reconheça que o apoiador do Nasf não apoia sozinho, ele também precisa de suporte, seja por meio de AI para o AM, supervisões clínico-institucionais, espaços de educação permanente, reuniões de matriciamento ou com outros serviços da rede. Esses encontros podem se configurar como espaços de formação, assim como cursos e capacitações específicas, que, quando ofertados pelos gestores, muito têm a qualificar o trabalho dos profissionais do Nasf, principalmente no que tange à dimensão técnico-pedagógica, pouco presente nas formações acadêmicas.

Outro aspecto sobre o qual caberia à gestão 'apoiar' o trabalho do Nasf se refere à situação das EqSF: se estão completas, se cobrem áreas com demanda assistencial intensificadas, se estão abertas para receber apoio. Isso pode influenciar de forma negativa ou positiva a relação das EqSF com os apoiadores e a realização do apoio matricial, a depender de como for construída a demanda, os fluxos de acesso, o planejamento do trabalho conjunto entre profissionais etc. ${ }^{26}$. É necessária uma atmosfera razoavelmente favorável ao apoio nas EqSF, e os gestores são atores centrais nesse processo.

O planejamento das ações deve se pautar pelas necessidades dos grupos apoiados pelo Nasf - EqSF e população atendida -, não sendo limitado ao papel de cada profissional ${ }^{40}$. Para isso, a estruturação dessas equipes precisa 
estar de acordo com a situação e com o perfil técnico, epidemiológico, sanitário e social das EqSF e usuários. Por exemplo: para um território com alta vulnerabilidade social, profissionais do serviço social e psicologia podem ser priorizados na composição do Nasf, assim como médicos pediatras seriam prioritários em territórios com alto número de crianças, ou equipes que apresentam fragilidade no cuidado delas. Partir do conhecimento das EqSF acerca dos problemas de saúde do seu território, "mais do que gerenciar recursos e os dados burocráticos dos sistemas de informação" importante diretriz para gestores que desejam mudanças mais efetivas.

Para finalizar, destacamos um breve apontamento sobre a necessidade de conexão entre os processos de avaliação e monitoramento do Nasf e das EqSF, uma vez que, trabalhando juntos, produzem impacto sobre os mesmos fenômenos. Em outras palavras, é razoável supor que os efeitos do trabalho do Nasf também podem ser observados, ainda que de forma indireta, por meio dos resultados do trabalho das EqSF, se for levado em conta que estas e os usuários em seus territórios são 'objeto' de trabalho dos apoiadores matriciais. Há que se considerar, nesse sentido, a complexidade que se coloca para avaliar o Nasf ${ }^{26}$.

Diante do exposto, a dimensão de gestão se apresenta em destaque aqui por considerarmos relevante: a) afirmar esse aspecto como constitutivo da função 'apoio' e, consequentemente, do AM; b) trazer à tona as condições organizacionais de gestão para que o trabalho do Nasf possa se desenvolver em sua máxima potência.

\section{Considerações finais}

Os 10 anos de Nasf foram marcados, de um lado, por sua formulação inovadora enquanto arranjo, por importantes reformulações e reinvestimento, e pela sua implantação em todas as regiões do País, embora ainda não contemple a totalidade de municípios brasileiros. Por outro lado, tal processo vem sendo vivido, no cotidiano dos serviços, de modos heterogêneos e, por vezes, tensos. Acresce-se a essas questões o fato de que os Nasf atuam nas realidades também complexas das EqSF, em contextos de gestão e de redes de atenção locorregionais adversos. Esse cenário requer atenção constante a, pelo menos, dois planos: aquele normativo e nacional da política oficial; e aquele local, cotidiano, micropolítico. Ambos podem, constantemente, compor-se, influenciar-se ou ignorar-se. Neste sentido, consideramos que a potência dos Nasf depende de diferentes elementos que lhe são internos e externos. Nesse quadro, além de desafios mais gerais do SUS e da $\mathrm{AB}$, que, em parte, condicionam as possibilidades do Nasf, destacamos alguns elementos críticos específicos, referentes à formulação, inserção na rede e gestão, discutidos ao longo deste texto.

Para lidar com essas questões, alguns investimentos parecem-nos fundamentais. $\mathrm{O}$ primeiro deles diz respeito à formação em saúde: seria recomendável que a temática do Nasf e, especificamente, do AM, fosse tratada em todas as residências em saúde do País (médicas, não médicas e multiprofissionais), preparando não apenas os profissionais que pretendem trabalhar na $\mathrm{AB}$, mas também aqueles da atenção especializada, para oferecer apoio matricial. Na mesma medida, identificamos a necessidade de ampliação das ofertas de formação permanente aos profissionais do Nasf, em sintonia com as especificidades das composições da equipe e das necessidades de cada serviço e território. Faz-se necessária, também, a formulação de estratégias de avaliação, bem como estudos e pesquisas que evidenciem efeitos e resultados do Nasf para as EqSF e para os usuários. Por meio de parcerias entre governos e entidades de ensino e pesquisa, seria recomendável o incentivo para que tais estudos desenvolvessem metodologias sensíveis à abrangência e heterogeneidade das experiências de trabalho do Nasf e, ao mesmo tempo, estruturassem-se de modo multicêntrico, abarcando diferentes realidades. 
Enfrentar os desafios aqui discutidos com mais vigor, sem desconsiderar a diversidade e desigualdade existentes no 'Brasil profundo', parece ser vital para a ampliação da capacidade de cuidado da $\mathrm{AB}$ que o Nasf, em última instância, objetiva. A recente mudança na $\mathrm{PNAB}$, ao suprimir a palavra 'apoio' da denominação oficial do Nasf, parece não encarar nem encorajar os gestores a enfrentar tais questões, ou talvez esteja a indicar intencionalidades (não explícitas) de mudanças mais substanciais nos tipos de apostas.

\section{Colaboradores}

Melo EA, Miranda L, Silva AM e Limeira RMN contribuíram substancialmente para a concepção, planejamento, análise, elaboração do rascunho, revisão crítica do conteúdo e aprovação da versão final do manuscrito.

\section{Referências}

1. Viana AL, Dal Poz MR. A reforma do sistema de saúde no Brasil e o Programa de Saúde da Família. Physis. Rio de Janeiro. 2005; 15(supl):225-264.

2. Escorel S, Giovanella L, Mendonça MHM, et al. Avaliação da implementação do Programa Saúde da Família em dez grandes centros urbanos: síntese dos principais resultados. 2. ed. Brasília, DF: Ministério da Saúde; 2005.

3. Machado CV. Direito Universal, política nacional; o papel do Ministério da Saúde brasileira de 1990 a 2002. Rio de Janeiro: Museu da República; 2007.

4. Macinko J, Oliveira VB, Turci MA, et al. The influence of primary care and hospital supply on ambulatory care-sensitive hospitalizations among adults in Brazil, 1999-2007. Am. J. Public Health. 2011 Oct 17; 101(10):1963-70.

5. Merhy EE, Franco TB. PSF: contradições de um programa destinado à mudança do modelo tecnoassistencial. In: Merhy EE, Magalhães Júnior HM, Rimoli J, et al., organizadores. O trabalho em saúde: olhando e experienciando o SUS no cotidiano. São Paulo: Hucitec; 2003.

6. Brasil. Ministério da Saúde. Portaria $n^{\circ} 154$, de 24 de janeiro de 2008. Cria os Núcleos de Apoio à Saúde da Família - NASF. Diário Oficial da União. Brasília, DF, 25 Jan 2008. [acesso em 2012 abr 15]. Disponível em: http://bvsms.saude.gov.br/bvs/saudelegis/gm/2008/prt0154_24_01_2008.html.

7. Brasil. Ministério da Saúde. Histórico de cobertura SF. [acesso em 2018 jul 25]. Disponível em: http:// www.saude.gov.br/dab.

8. Campos GWS, Domitti AC. Apoio matricial e equipe de referência: uma metodologia para gestão do trabalho interdisciplinar em saúde. Cad. Saúde Pública, 2007; 23(2):399-407. 
9. Campos GWS, Pereira Júnior N. A Atenção Primária e o Programa Mais Médicos do Sistema Único de Saúde: conquistas e limites. Ciênc Saúde Colet., 2016; 21(9):2655-2663.

10. Fausto MCR, Giovanella L, Mendonça MHM, et al. A posição da Estratégia Saúde da Família na rede de atenção à saúde na perspectiva das equipes e usuários participantes do PMAQ-AB. Saúde debate [internet]. 2014 [acesso em 2014 nov 1]; 38(esp):1333. Disponível em: http://www.scielo.br/pdf/sdeb/ v38nspe/0103-1104-sdeb-38-spe-0013.pdf.

11. Brasil. Ministério da Saúde. Portaria, $\mathrm{n}^{\circ}$ 3124, de 28 de dezembro de 2012. Redefine os parâmetros de vinculação dos Núcleos de Apoio à Saúde da Família (NASF) Modalidades 1 e 2 às Equipes Saúde da Família e/ou Equipes de Atenção Básica para populações específicas, cria a Modalidade NASF 3, e dá outras providências. Diário Oficial da União. 28 Dez 2012. [acesso em 2013 dez 15]. Disponível em: http://bvsms.saude.gov.br/bvs/saudelegis/ gm./2012/prt3124_28_12_2012.html.

12. Brasil. Ministério da Saúde. Secretaria de Atenção à Saúde, Departamento de Atenção Básica, Núcleo de Apoio à Saúde da Família. Cadernos de Atenção Básica, número 39. Brasília, DF: Ministério da Saúde, 2014.

13. Melo EA, Vianna EC, Pereira LA, organizadores. Caderno do curso Apoio matricial na atenção básica com ênfase nos NASF: Aperfeiçoamento. 2. ed. Rio de Janeiro: Fiocruz, 2016.

14. Sampaio J, Sousa CSM, Marcolino EC, et al. O NASF como dispositivo da gestão: limites e possibilidades. Rev. Bras. Ciênc. Saúde. 2012; 16(3):317-324.

15. Araújo EMD, Galimbertti PA. A colaboração interprofissional na estratégia saúde da família. Psicologia \& Sociedade. 2013; 25(2):461-468.

16. Barros J, Gonçalves MRA, Kaltner RP, et al. Estratégia do apoio matricial: a experiência de duas equipes do Núcleo de Apoio à Saúde da Família (NASF) da cidade de São Paulo, Brasil. Ciênc Saúde Colet. 2015; 20(9):2847-2856.
17. Tesser CD. Núcleos de Apoio à Saúde da Família, seus potenciais e entraves: uma interpretação a partir da atenção primária à saúde. Interface comun. Saúde Educ. 2017 set; 21(62):565-578.

18. Campos GSW, Guitérrez AC, Guerrero AVP, et al. Reflexões sobre a Atenção Básica e a estratégia de saúde da família. In: Campos GSW, Guerrero AVP. Manual de práticas de atenção: Saúde ampliada e compartilhada. 2008. p. 132-254.

19. Brasil. Ministério da Saúde. Portaria $n^{\circ} 648$, de 28 de março de 2006. Aprova a Política Nacional de Atenção Básica, estabelecendo a revisão de diretrizes e normas para a organização da Atenção Básica para o Programa Saúde da Família (PSF) e o Programa Agentes Comunitários de Saúde (PACS). Diário Oficial da União. 26 Mar 2006.

20. Brasil. Ministério da Saúde. Secretaria de Atenção à Saúde, Departamento de Atenção Básica, Núcleos de Apoio à Saúde da Família. Cadernos de Atenção Básica, número 27. Brasília, DF: Ministério da Saúde; 2010.

21. Brasil. Ministério da Saúde. Secretaria de Atenção à Saúde, Núcleo Técnico da Política Nacional de Humanização. HumanizaSUS: Documento base para gestores e trabalhadores do SUS. 4. ed. Brasília, DF: Ministério da Saúde, 2008.

22. Moura RH, Luzio CA. Apoio institucional como uma das faces da função apoio no Núcleo de Apoio à Saúde da Família (NASF): para além das diretrizes. Interface Comum. Saúde Educ. 2014; 18(supl.1):974986.

23. Bower P. Primary Care mental health workers: models of working and evidence of effectiveness. J R Coll Gen Pract: 2002; 52:926-933.

24. Gagné MA. Avancement des objectifs des soins de santé mentale axés sur la collaboration. Mississauga: Initiative canadienne de collaboration en santé mentale, maio 2005.

25. Saraiva S, Zepeda J. Princípios do Apoio Matricial. 
In: Gusso G, Lopes JMC, organizadores. Tratado de Medicina de Família e Comunidade. Porto Alegre: ArtMed; 2012.

26. Correia PCI, Goulart PM, Furtado JP. A avaliabilidade dos Núcleos de Apoio à Saúde da Família (Nasf). Saúde Debate. 2017 mar; 41(supl):345-359.

27. Bezerra E, Dimenstein M. Os CAPS e o trabalho em rede: tecendo o apoio matricial na atenção básica. Psicol. Ciênc. Prof. 2008; 28(3):632-645.

28. D'Amour D, Goulet L, Labaide J-F, et al. A Model and Typology of Collaboration between Professionals in Healthcare Organizations. BMC Health Services Research [internet]. $2008 \mathrm{dez}$ [acesso em 2018 maio 24]; 8(1):188. Disponível em: http:// bmchealthservres.biomedcentral.com/articles/10.1186/1472-6963-8-188.

29. Furtado JP. Equipes de referência: arranjo institucional para potencializar a colaboração entre disciplinas e profissões. Interface Comum. Saúde Educ. 2007 ago; 11(22):239-55.

30. Silva EM, Moreira MCN. Equipe de saúde: negociações e limites da autonomia, pertencimento e reconhecimento do outro. Ciênc Saúde Colet. 2015; 20(10):3033-3042.

31. Brasil. Ministério da Saúde. Portaria, $n^{\circ}$ 2.436, de 21 de setembro de 2017. Aprova a Política Nacional de Atenção Básica, estabelecendo a revisão de diretrizes para a organização da Atenção Básica, no âmbito do Sistema Único de Saúde (SUS). Diário Oficial da União. 21 Set 2017.

32. Brasil. Ministério da Saúde. Secretaria de Atenção à Saúde. Departamento de Atenção Básica. Política Nacional de Atenção Básica. Brasília, DF: Ministério da Saúde, 2012.

33. Brasil. Ministério da Saúde Portaria n ${ }^{\circ} 4.279$, de 30 de dezembro de 2010. Estabelece diretrizes para a organização da Rede de Atenção à Saúde no âmbito do Sistema Único de Saúde (SUS). Diário Oficial da União. 30 Dez 2010.

34. Cecilio LCO, Andreazza R, Carapinheiro G, et al. A Atenção Básica à Saúde e a construção das redes temáticas de saúde: qual pode ser o seu papel? Ciênc Saúde Colet. 2012; 17(11):2893-2902.

35. Castro CP, Campos GSW. Apoio Matricial como articulador das relações interprofissionais entre serviços especializados e atenção primária à saúde. Physis 2016; 26(2).

36. Cunha GT, Campos GWS. Apoio Matricial e Atenção Primária em Saúde. Saude soc. 2011; 20(4):961970.

37. Magalhães Júnior HM. Redes de atenção à saúde: rumo à integralidade. Divulg. saúde debate. 2014; (52):15-37.

38. Tesser CD, Poli Neto P. Atenção especializada ambulatorial no Sistema Único de Saúde: para superar um vazio. Ciênc. Saúde Colet. 2017; 22(3):941-951.

39. Panizzi M, Lacerda JT, Natal S, et al. Reestruturação produtiva na saúde: atuação e desafios do Núcleo de Apoio à Saúde da Família. Saúde debate 2017; 41(112):155-170.

40. Andrade LMB, Quandt FL, Campos DA, et al. Análise da implantação dos Núcleos de Apoio à Saúde da Família no interior de Santa Catarina. Saúde Transform. Soc. [internet] 2012 jan [acesso em 2018 maio 22]; 3(1):18-31. Disponível em: http://pepsic.bvsalud.org/scielo.php?script=sci_arttext\&pid=S2178$-70852012000100005 \& \operatorname{lng}=\mathrm{pt} \& \mathrm{nrm}=$ iso.

Recebido em 29/05/ 2017

Aprovado em 10/08/2018

Conflito de interesses: inexistente

Suporte financeiro: não houve 